\title{
Musical Exploration via Streaming Services: The Norwegian Experience
}

\section{Yngvar Kjus}

\begin{abstract}
Streaming services for music are growing worldwide, and the Nordic countries are leading the way. In Norway, streaming represented 88 percent of digital music revenues in 2014, as opposed to 23 percent globally. In essence, streaming services offer subscribers access to vast databases of music, and offer artists new means of exposure and sources of revenue. This article argues that the possibility of musical discovery is essential to these services' distribution model. It examines the provisions for exploration through streaming, pointing to automated algorithms and human curation as key devices. It then collects quantitative data on the presentation of music via a Norwegian service (WiMP/Tidal) and qualitative findings from interviews with consumers about their experiences with music streaming. Key discrepancies arise between the promise and the reality of streamed-music discovery, both for artists seeking new fans (and funds) and for audiences expecting streaming to supersede existing forms of musical exploration.
\end{abstract}

Keywords: Music discovery, distribution, streaming services, curation, playlists, algorithms

\section{Introduction}

WiMP is a music service that inspires you to find new music and old favourites. Our local editorial teams give you daily tips, recommendations and playlists for any occasion.- www.WiMP.no

All your music is here. Spotify gives you millions of songs at your fingertips. The artists you love, the latest hits, and new discoveries just for you. Hit play to stream anything you like.-www.Spotify.com

These quotations from the self-promotion of the two largest Nordic streaming services, the Norwegian WiMP and the Swedish Spotify, feature everything from the insight of guidance by local experts to the thrill of charting one's own path, but discovery is clearly a key selling point for both. Both are fairly young champions of the streaming model of music distribution (WiMP was launched in 2010, Spotify in 2008), which essentially involves access to vast musical archives of millions of tracks in exchange for a monthly subscription fee (typically ten Euros) or advertising exposure. Streaming services represent an abrupt and significant shift away from the established models of selling musical items, whether physical records or downloadable files; in fact, while streaming represented 14 percent of the total revenues of the consumer market for recorded music in Norway in 2010, it grew to an astonishing 75 percent in 2014 
(International Federation of the Phonographic Industry [IFPI], 2015), a year in which it was, in fact, CD sales that accounted for only 14 percent of the revenues. The streaming service model therefore marks a new chapter in the development of the music industry, in cultural as well as economic terms, not least by heralding a new era for musical exploration and immersion.

The rise of streaming services begs the question of the actual extent to which the promotional trope of 'discovery' is realised through them. Are artists, in fact, finding new supporters, and are listeners enjoying new exploratory experiences with this music? Throughout the 2000 s, the provision of products via large online databases has been associated with various benefits, including those of the 'long tail', a term coined by Chris Anderson (2006), editor of the tech magazine Wired. Essentially, the long tail describes a new, digitally driven space for niche and specialised interests. While the contemporary streaming service has certainly cultivated and capitalised upon this notion, little is known about how streaming-related 'long tail' discoveries take place. There is a particular lack of awareness of the key role performed by music distributors - Shuker (2013, p. 116) even concedes, 'There is a history of music retail yet to be written'. In what follows, I will therefore propose alternative approaches to the forms and effects of music distribution via streaming services. First, I will present an industry-level assessment of the novelty of the streaming model, identifying and comparing the discovery-related strategies of key players. Next, I will examine the offerings of the Norwegian streaming service WiMP (recently renamed Tidal after the purchase of the company by the American artist Jay-Z) and specifically its provision of playlists featuring artists from its database. Last, I will present findings from group interviews with music streamers in Norway, focusing on their sense of discovery through streaming.

While the rise of streaming services is a global phenomenon, the Nordic countries are at its forefront, in terms of industry innovation as well as user appropriation. Sweden was where the Pirate Bay developed its controversial peer-topeer systems of free filesharing, and where Spotify launched its streaming model as an alternative to blatant piracy. In Norway, the market success of these distributors has been linked to the subsequent closure of many CD shops, though the largest CD retail chain answered the challenge by investing in its own streaming service, called WiMP. In Norway, Spotify and WiMP have long dominated the distribution market, and, in fact, by 2014 seven out of ten Norwegian Internet users accessed one of these services (TNS Gallup, 2014). The surge in use of music streaming services in Norway most likely relates to the nation's high level of broadband diffusion and comparatively small music market. Already in 2011, 48 percent of Norwegian music consumers used a streaming service, compared with 43 percent in Sweden, 32 percent in the United States, and 18 percent in the UK (Mulligan, 2012). After a tumultuous period in which alternative forms of distribution have multiplied, then, the Nordic population has clearly gravitated towards a streaming model that is associated with a few large providers serving vast numbers of users. This alignment, in turn, merits scrutiny.

\section{Distribution and Discovery}

Distributors have fundamental limitations to their means of providing an experience of discovery. Distribution, first of all, refers to the music industry practice organised by professionals and companies to profit commercially by acting as an intermediary between artists and labels, on the one hand, and consumers, on the other. The term discover, in turn, derives from the Latin dis (reversal) and cooperire (complete 
coverage), thus evoking individual actions that make hidden things known but also the subjective experience of realising something new. For artists, it can be hugely rewarding to 'discover' new fans; for listeners, it can be equally exciting to 'discover' artists and songs that truly touch them. What is discovered, and in some ways what it feels like to discover, is essentially unpredictable.

Since its inception, of course, the music industry has sought predictable mechanisms through which to control what music people come across and to encourage them to buy it. Enticing physical presentations and promotions in record stores and outlets have always comprised one strategy, but industry professionals know that this is not enough. Artists themselves contribute to the larger effort by going on tour or producing music videos, posters and other promotional materials. While it is an established fact that the live concert experience can trigger record sales (Burnett and Weber, 1989), most concertgoers already know the artist in question. In order to introduce new or unfamiliar music to the record-buying public, then, media exposure has been particularly crucial, via the playlists of popular radio channels (Hirsch, 1970) and the music press (Frith, 1983), among other things. Importantly, the DJs, critics and journalists working in the media have long decided for themselves what to cover, thus substantiating the validity of their playlist choices. The intermediaries of rock have been particularly astute in this regard, claiming 'criticism rather than puffery as the essence of their job' (Frith, 1983, p. 174).

The impact of these established sales triggers has changed, however. In economic terms, the gain from media exposure was based on what Wikstrøm (2009, p. 90) called 'option values', meaning that buying the record was positioned as offering something markedly different from hearing the music via other means. For many years, the added value of buying records included the ability to decide when and where to listen to what. In the $2000 \mathrm{~s}$, this ability has accompanied the rise of online and mobile media as well, via sanctioned (e.g., MySpace) and unsanctioned (e.g., Pirate Bay) services. As music distribution began to transcend established retailers, of course, these means of generating exposure were decoupled from a system for securing sales. Time-honoured industry logics were thereby overturned, and this included a much-publicized reversal of the relationship between concerts and records: concerts, which used to be regarded as promotion, have now become the primary revenue source, while record releases now serve as commercials for ticket sales (see, for example, Rogers, 2013).

It was amid this industry turbulence that a series of technology corporations managed to persuade the music industry to test new distribution models, including the iTunes Music Store (established 2003) and Spotify (launched 2008). The former offered downloads for sale, thus representing an online perpetuation of a century-old retail model. The latter, on the other hand, asked artists and labels to sign over the distribution rights to their entire musical catalogues, which were then offered to consumers for a flat monthly fee (or through advertising exposure). Individual artists received remuneration according to how much they were streamed. In this model, 'all' of the artists are instantly and easily available to 'all' of the listeners, and visa versa. Streaming services thereby introduce a new relation between exposure and sale, united within one and the same service. This is an uneasy relationship, however, particularly given that listening to a streamed song generates much less revenue that selling it. Notably, as well, whereas a sale triggered immediate compensation, regardless of how often the buyer played the song, streaming is based on accumulated listening over time. In the era of physical retail, then, people selling records mainly needed to stimulate a sense of discovery up until the act of buying. Streaming revenues, 
conversely, depend on the continuous engagement of people who both discover and replay the music.

Overall, streaming services present artists and labels with new dilemmas, as illustrated by the quandary of the Norwegian artist Susanne Wallumrød, who, after a period of abstinence, decided to try streaming: 'I am tired of excluding the audience from my music, but I also find it problematic to convey to the same audience that I am left with too little money from a legal service that many actually pay for' (Østrem, 2014). Even as Wallumrød was putting her music on Spotify so that her fans could find her there, later in 2014 the (already world-famous) American artist Taylor Swift withdrew hers from the same platform, insisting that 'valuable things should be paid for' (Ellis-Petersen, 2014). To this widely publicised challenge, Spotify founder Daniel Ek promptly responded as follows: 'Our whole reason for existence is to help fans find music and help artists connect with fans through a platform that protects them from piracy and pays them for their amazing work' (Ek, 2014).

This recent spat demonstrates the unresolved tensions between reach and revenue via streaming. The new distribution model depends not only on artists' and labels' trust in the upside of lending the streaming services their music but also on the appropriation and appreciation of streaming by subscribers. The quotes at the beginning of this article illustrate how streaming services now invest heavily in trying to define the best way to explore music. In this, of course, Spotify and WiMP compete not only with one another but also with a range of other services aimed at a global market, including Google Play, Beats, Sony Music, Deezer and Rdio. The degree to which these services manage to convince artists, labels and consumers of the virtues of discovery may well be decisive for the future of the streaming model.

\section{Nordic Takes on Streaming}

The rise of streaming services (collectively and individually) must be understood within a particular historical and industrial context. Spotify, for example, was conceived and developed as an explicit response to the 'piracy' and unsanctioned peerto-peer distribution that proliferated on the Internet in the early 2000s. Famously, the launch of Napster in 1999 inspired a range of services that allowed users to share and explore music in the company of peers around the world, and outside the control of established music distributors (Andersson Schwarz and Burkart, 2015). Spotify presented itself to labels and artists as a legal and potentially profitable alternative means of online distribution, and the major labels (Sony, Universal, Warner and EMI) were persuaded to not only offer access to their music but also buy shares in the service. To the consumers, Spotify was marketed as a user-friendly super-service that at last outshined the virtues of free filesharing. Spotify's claims were recently validated by a survey showing that the share of people who downloaded music without paying in Norway had dropped from 70 percent of those under thirty years old in 2009 to only 4 percent of that age bracket in 2014 (IFPI, 2015). The developers and programmers at Spotify benefited from their insight into the services they were challenging-Daniel Ek, for example, managed a popular BitTorrent client before founding Spotify. The new streaming service was intended to make finding and sharing music even easier, and it invested heavily in advanced search engines, comprised of automated algorithms that linked related artists and featured recommendations based on the individual listener's prior use. Spotify has since proved to be exceedingly popular-by 2010 it had topped 10 million users (and by 2015, it could boast 75 million users). 
Many artists and labels were reluctant regarding Spotify, however, finding that it favoured the rights holders of music catalogues that were already popular at the expense of relative newcomers (Bishop, 2013). These perceived shortcomings, in turn, left room for other services to present (presumably) superior legal alternatives to piracy. In Norway, the arrival of iTunes in 2005 and Spotify in 2008 hastened the demise of the $\mathrm{CD}$, as mentioned above, and prompted the leading national retail music chain, Platekompaniet, to invest in its own streaming service, together with the technology company Aspiro and the telecom Telenor. This service, called WiMP, was explicitly promoted as a local streaming alternative, one that aided 'Norwegian artists to find their Norwegian fans', and vice versa. While WiMP also signed deals with the four major labels, the service made a point of inviting smaller independent labels to cooperate on tailor-made releases and campaigns. It also developed a program, called WiMP DIY, for featuring and funding unsigned local talents. In order to emphasise the local aspect, the service established an editorial team with in-depth local knowledge. WiMP's editors curated everything that was featured in the various campaigns and musical categories of the service, to the extent of dismissing the option of advertising spots. By the end of 2010, WiMP had recruited 100,000 paying subscribers, and by 2015 it could boast 500,000, attesting to the appeal of the editorial touch, which remained its trademark when the service was introduced to the other Scandinavian countries, and then (in 2014) to several other European countries and the United States (under the name 'Tidal'). Its artist-friendly profile helped to convince several artists to submit their music to the service and ultimately persuaded American rapper and entrepreneur Jay-Z to buy it in 2015 via his company Project Panther Bidco. The new owner has continued to emphasise the service's fairness to artists, and particularly its editorial profile: 'The playlists on TIDAL are tailor-made for our listeners, expertly curated by our team, and not by a computer algorithm' (www.Tidal.com).

This brief chronology of streaming in the Nordic countries reveals that the two largest services invested in opposite modes of discovery: automated algorithms and human curation. An early signature application on Spotify clustered so-called 'related artists', guiding fans of one artist to others that they might like. Such recommendations are based on quantitative estimations of similarities in the database of the service, with regard to previous user behavior and/or the music itself. In a continuous effort to identify taste patterns, Spotify later partnered with the music website Last.fm and recently bought the Echo Nest, which refers to itself as a 'music intelligence platform'. The better Spotify's algorithms become at estimating similarity, however, the more susceptible they are to the following evaluation of Burkart and McCourt (2006, p. 98): 'Such systems make it unlikely that listeners will be exposed to unfamiliar genres and develop new tastes and interests'.

From the outset, all the music that WiMP featured on its landing page and through its musical categories was selected by its staff members. Curation, as opposed to algorithms, depends upon the judgments of an expert who determines what is interesting, valuable or significant. The challenge here is that the preferences and priorities of individual curators can differ radically from those of the bulk of the intended audience. WiMP responded to this limitation by asking artists and journalists of different genres to create and feature playlists in the service as well, even as the staff continued to produce most of the editorial campaigns. Users could also search directly for artists, albums and songs in the database, and after a few years WiMP added a functionality that proposed 'similar artists' in relation to these searches. This application, and the algorithms upon which it was based, was provided by Rovi, a company devoted to 'recommendation services'. In the intermediary efforts of WiMP 
and in the user experience offered to its subscribers, then, the editorial profile remained essential.

The algorithms and curators involved with streaming are likely to have a growing impact on the music that is discovered, listened to and paid for. So far, however, there has been a dearth in research aimed at the implementation and appropriation of streaming. As mentioned above, Norway is a fitting place to start, given its vanguard position in music distribution. Already in 2011, sales of digital formats matched physical formats, with streaming constituting 35 percent of all revenues (IFPI, 2015). In 2012, the total revenues from recorded music sales finally began to grow again, after a decade-long drop, making that year particularly interesting for the study of digital transitions in the music industry.

In the following section, I will present the development of the editorial profile of the Norwegian service WiMP through interviews with key personnel, as well as data on the provision of curated playlists and their streaming in 2012.

\section{Curating the Streams}

When the record store chain Platekompaniet teamed up with the technology company Aspiro and the telecom Telenor to create WiMP, the chain was supposed to 'take care of the music, while the two others handled the technology', said the freshly installed head of editorial campaigns. A WiMP editorial team was promptly established with two editors who used to work in Platekompaniet's record stores and one former music journalist to serve as editor-in-chief. In 2012, I carried out four interviews with this team, which had been given the daunting task of organising the presentation of WiMP's twenty million tracks.

The conditions for curation were indeed formidable. During the night, tens of thousands of new tracks might be added to the vast WiMP database from any of the record companies and rights holders that had signed with the service. As only a fraction of this material could be considered for front-page visibility, WiMP soon developed four editorial priorities: (1) local music, (2) new music, (3) relevant and inspiring music, and (4) serendipity (the happy surprise). These priorities have since been formalised in a so-called 'bible' for the use of editorial teams that have arisen in new countries. They reflect WiMP's commitment to the artists and labels that are seeking effective distribution - a commitment which is also represented in the primary presentational categories on its landing page, titled 'news', 'recommended' and 'playlists'. New record releases are continuously channelled into the news category, and an extra effort is made to include Norwegian material, to the delight of many Norwegian artists. The releases that prove to be particularly popular or noteworthy are then apportioned into the recommended category, which was divided in 2015 into 'Tidal Rising', for artists who already have 'a passionate fan base', and 'Tidal Discovery', for 'talented unsigned artists'. This move further demonstrates the service's commitment to all artists and labels, not only the major ones, a commitment that was further supported by the fact that it is not possible to buy oneself into these presentational categories. Of course, artists who were able to deliver on these editorial priorities could negotiate good visibility, for example by offering access to exclusive pre-releases of their upcoming music. This bourgeoning barter system reflected the fact that the editors sought a balance between the needs of the artists and the need to appeal to subscribers.

While the news and recommendations categories were inherited from Platekompaniet, the playlists category was an innovation-one to which the editors 
attached the most prestige in terms of curation and length of exposure in the streaming service. WiMP gave me access to the log files of its playlists throughout 2012, for a total of 356 lists. The largest group of playlists presented new releases, many via weekly bulletins called 'Music Monday' and 'Ten for Friday' which usually contained between ten and thirty tracks. Many playlists also featured the music of artists who were about to perform concerts or who were featured in the media. Fifty-seven percent of the lists had this 'breaking-news' orientation, whereas 34 percent were historical excavations of the archives, sometimes exceeding one hundred tracks, through which WiMP would present the story of a genre or an artist (for example, 'Essential Hip-Hop 2001-2010') or respond to some timely trigger (for example, 'R.I.P. Whitney Houston 1963-2012'). Lastly, WiMP presented a handful of lists associated with events and activities outside the music arena, both public (such as 'The Summer Olympics') and private (such as 'The Sound of Summer' or 'Easter Party 2012'). My overview from 2012 demonstrates that the editors were indeed focused on helping artists and labels release new music via their playlists, even as they tried to help subscribers strike gold in the archives as well.

But to what extent did the curation of playlists actually spark discovery? Data on subscribers' streaming of playlists is one potential entry point regarding this query, and I acquired this data from WiMP for the summer of 2012. It shows that the lists presenting new tracks would usually shoot upward in popularity when first released and then fall back again within a week (see the graph for the list 'Music Monday' in figure 1). The lists presenting upcoming concerts, conversely, tended to increase in popularity in the week preceding the performance, then drop off rapidly afterwards (see 'Øya Festival on Friday' in the same graph). The historical compilations differed yet again, in that they would fade in popularity more slowly (see, for example, 'Essential Hip-Hop 2001-2010') - these kinds of lists were likely to be relevant for a longer period of time and were also capable of engaging fans of the particular musical theme in repeated listening. Finally, the lists that were adapted to the contexts and activities of users were prone to even lengthier curves of popularity. As in the example 'The Sound of Summer' in the graph, lists of this kind were well suited to recurrent front-page promotion (triggering new streaming peaks), depending on the duration of the list's topicality. This data indicates the emergence of new patterns in playlist use via streaming, as opposed to the more stable reach and recurrent rotation of the playlists of, for example, radio stations. 


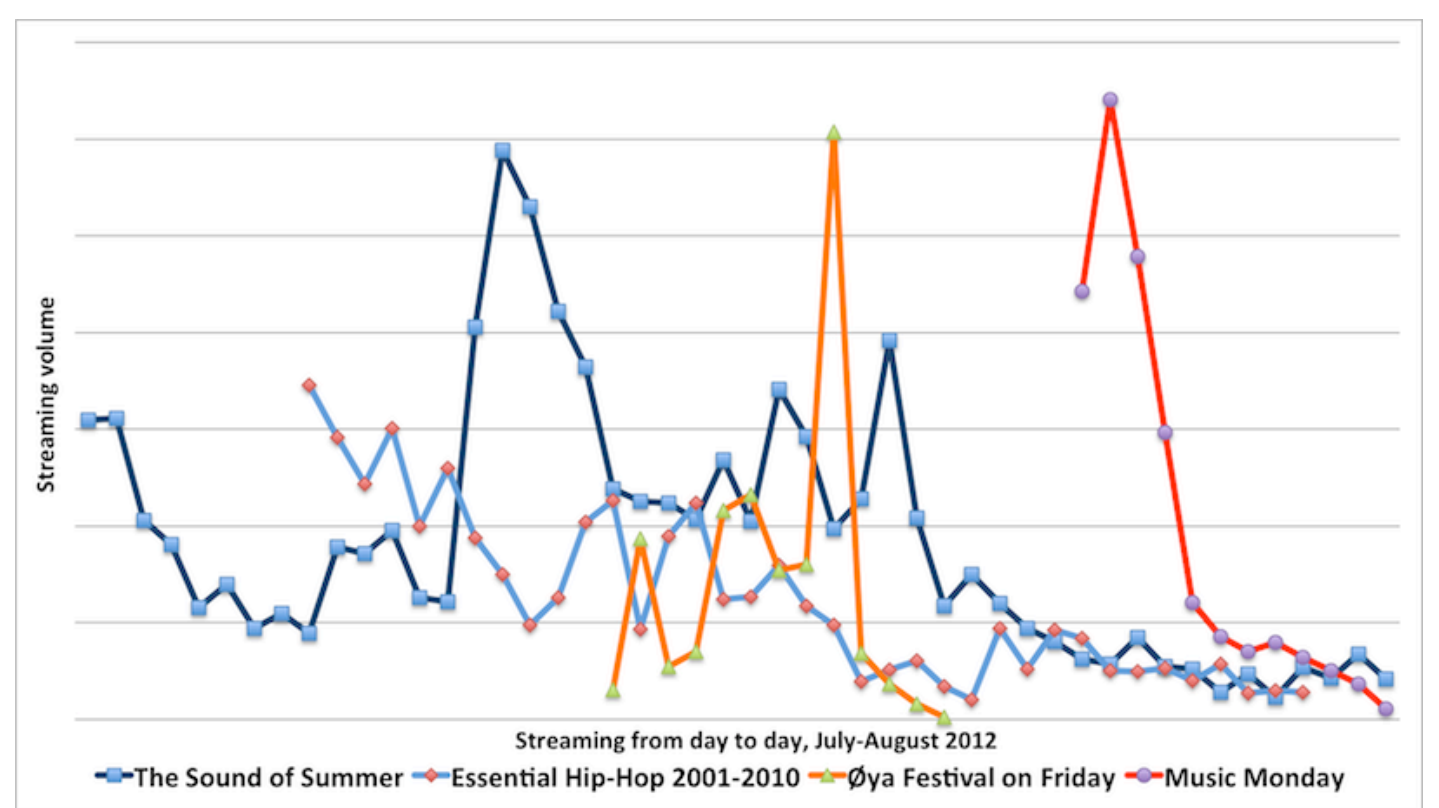

Figure 1. Streaming volume of a selection of WiMP playlists from day to day in July and August 2012. The streaming of 'The Sound of Summer' exceeded that of the other lists and has been divided by 2.5 times to fit into the same chart. (The exact number of streams behind each graph is not disclosed, as agreed upon with the streaming service.)

It appears that the lists that present news and upcoming events are good at triggering a short-term exposure, which climbs and falls quickly, whereas lists that plumb the depths of the archives or relate to peoples' lives lend themselves to longer-term experiences. Although WiMP prioritised the former in 2012, it is quite possible that the latter prompted more streaming, as well as more discovery, here understood as an opening up of people's ears and a clearing of space for new music in their hearts and minds.

What this playlist data does not tell us, however, is the extent to which exposure to new music impacts what people listen to beyond the curated playlist, whether via personal playlists or concert attendance. Furthermore, the data cannot encompass whether the streaming in question represents an encounter with unfamiliar music (or whether the user, on the other hand, was already aware of it or even a fan). To find out where and how discovery takes place, then, one must go beyond the consumption data of music services to look at the discoverers themselves.

\section{Maneuvering in the Streams}

Focus-group interviews are a suitable method for obtaining numerous viewpoints on and varied experiences with a phenomenon (Lunt and Livingstone, 1996). In August 2012, then, four group interviews were carried out with music streamers in Norway, totaling twenty-seven informants (fifteen women and twelve men) with an average age of twenty-eight (ranging from twenty-two to thirty-eight). All of the informants subscribed to streaming services and generally considered themselves to be music enthusiasts, but they were also old enough to remember how they discovered music before these services arose. Although the information they provided is not representative of the larger population, then, it can supply valuable insights into the 
attitudes and practices of key segments of the user base of new online music services (all quotes have been translated into English by the author).

Above all, the group interviews revealed a variety of sources for musical inspiration, including a plethora of media outlets (from films to blogs) and concert events (in keeping with the distribution model of Burnett and Weber, 1989). These people's most important source of discovery, however, was comprised of their friends and acquaintances, and several informants indicated that their social interaction not only triggered exploration but also constituted a musical experience in its own right. Here is one telling conversation excerpt:

The talk about music sharing tends to be all about digital sharing, but it is really much more. I don't share many links, but I play songs aloud to a person, directly. Because then I can convey my enthusiasm, saying things like 'Listen to this, this part is fantastic!' (Kristin, age 22)

You can send and receive tasters online, but I also like it when songs are played aloud for one other, whether at home or with friends. Or by going to a concert together, simply sharing the music then and there. (Ingrid, age 35)

While social music events are described as powerful opportunities for musical exploration, streaming services are usually where my informants went to follow up on these possibilities, even in the period before the actual event:

I usually put together my own playlist in WiMP in the period leading up to a music festival - [one] that I use to check out most of the new bands. I know that WiMP also provides festival lists, which I sometimes use, copying the ones I like into my own list. (Lisa, age 26)

The informants gave several accounts of musical events that sent them digging for more music in the streaming service. While discovery generally originated outside the services for most of the informants, the services were also perceived to be sites of exploration in their own right. Curated playlists, which could provide both historical compilations and contemporary updates, as well as the algorithms that point to 'similar artists', were all mentioned as useful tools.

Sometimes I go and see if WiMP has made some new playlists: perhaps some critic has made a compilation, or maybe one of the artists I know has released something. I seldom pick up entirely new things - instead I use it [the streaming service] as a kind of kitchen that I hang around in. (Vera, age 33)

Last summer I was going on a road trip up north in Norway, and then we wanted to bring along northern music. Then I began by searching for Halvdan Sivertsen, and then the 'similar artists' function was perfect, giving us K. M. Nyland and others from the region. (Mari, age 27)

When using these prompts to delve into the archives, my informants also typically created personal playlists to comprise a kind of notebook with which interesting items could be tracked for later use. This practice evokes WiMP's news lists, demonstrating the extended impact of these curatorial efforts. 
However, some of the informants also gestured towards the limitations of both editorial and algorithm-based guidance:

I don't use WiMP's lists that much any more. I used to think they had an interesting editorial thing going on, but I think the recommendations are getting worse and perhaps more commercial - 'Now we recommend Vinni', for instance, which I don't like at all. (Chris, age 37)

The similar artist algorithm, it was always tragic and it's still hopeless. If you listen to Karpe Diem, you get Kurt Nilsen, for instance - the only thing they share is Norway. (Albert, age 26)

I think it works for very genre-specific music, where it is easier to find the other 'similar artists'. (Viktor, age 26)

Some of these streamers distrusted editorial decisions, even considering them to be an insult to the integrity of their own musical discretion. Others found that the suggestions for 'similar artists' did not correspond to their own judgments and disturbed their own senses of musical identity with artists whom they disliked.

Other informants even expressed a sense of being overwhelmed by the millions of tracks in the database, including in particular those who were simply sitting down to find music:

The Beach Boys always pop up in my mind when I'm punching in something to search for. [Laughs.] I never listen to them, but the Beach Boys always return when I'm stuck. The number of available tracks is so immense, you know. Where to begin? (David, age 29)

I find it completely overwhelming. I have kind of resigned from it all, because I can't relate to all the music in the whole world. (Peter, age 29)

I have stumbled across extensive back catalogues that I had never seen before, with old EPs and B-sides and things like that. Then, I guess . . . it's not always very interesting, but some if it has been fun to listen to. (Martin, age 26)

Some of the informants found it tiresome to delve into the archives, not knowing what the outcome might be. In fact, a pattern emerged where an initial streaming frenzy, often inspired by the rediscovery of some forgotten treasure from years past, tended to be followed by a phase characterised by a more prudent approach to the streaming service. This pattern, of course, could be related to the fact that these informants were people in their twenties and thirties who had grown up with other (older) music media and had yet to be entirely sold on the prospects of the newly arrived musical platform.

\section{The Prospects for Exploration via Streaming}

This article has engaged with an early but key stage in the formation of a new triangular relationship between artists/labels, streaming services and users. At this moment, WiMP/Tidal prioritised local artists and independent labels in an attempt to attract a segment of music fans that other, larger streaming services had not yet satisfied. While streaming services in general market their provision of opportunities 
for discovery, the Norwegian service offered a specific editorial touch in the interests of bringing artists and audiences together. Though many playlists were developed to promote artists with new releases, however, streaming data shows that such lists triggered short-term exposure rather than longer-term experiences. This is a challenge for the artists as well as the services, of course, because streaming revenues are not based on music sales but on accumulated listening sessions.

My interviews with subscribers also pointed to certain crucial limitations in the discovery triggers of the streaming services. The musical discoveries of most of these informants did not originate within the services but in inspiration from friends, the media and live music performances. Afterward, however, many of them would seek to deepen or extend the experience using the streaming services, indicating that they were coming to represent a vital archival resource for inspired hunters and gatherers. Both streaming data and interviews, then, point to the challenges of leading people to specific parts of the long tail, despite the promises of the streaming services to do so. The fact that some users appear to lose interest in the large databases after a period of initial fascination represents a future challenge for streaming services to overcome.

It is clear that the key industry strategy of attracting audiences via unique means of discovering music faces other challenges as well. While WiMP/Tidal sought credibility in their provision of discovery by asserting editorial independence, for example, the selection and presentation of music is obviously organised ways that serve the interests of WiMP too, particularly with regard to their attempts to please both artists/labels and audiences. This editorial function, in practice, encompasses both salesperson and consumer guide - for one thing, artists and music are never criticized as such. As Frith (1983, p. 173) points out, there is a long tradition of 'job mobility between rock journalism and rock publicity', but what we are seeing here is that these roles are being combined in new ways within the framework of streaming services. This development merits further study.

Likewise, the credibility of automated algorithms also relies on an impression of independence, in the sense that they are meant to be presenting the conclusions of disinterested machines, but developers nevertheless shape these systems in certain ways, and this warrants further examination as well. In the end, while the arrival of Internet was associated with a new era of direct exchange between artists and fans, the rise of streaming services appears to be driving a new 'wedge between production and consumption - between making music and listening to it' (Suisman, 2009, p. 17). It may be, then, that streaming services intervene even more extensively than preceding intermediaries, despite their claims to the contrary.

\section{References}

Anderson, C. (2006). The long tail: Why the future of business is selling less of more. New York: Hyperion.

Andersson Schwarz, J. \& Burkart, P. (2015). Piracy and social change. Popular Communication, 13, 1-5.

Bishop, B. (2013). Thom Yorke pulls music from Spotify, calls it unfair to new artists, 15 July. Retrieved from http://www theverge.com/2013/7/15/4523978/thom-yorkepull-albums-from-spotify-and-rdio-calls-them-unfair-to-new-artists. 
Burkart, P., \& McCourt, T. (2006). Digital music wars: Ownership and control of the celestial jukebox. Lanham: Rowman and Littlefield.

Burnett, R. \& Weber, R. P. (1989). Concentration and diversity in the popular music industry, 1948-1986. Paper presented at the 84th Annual American Sociological Association Conference, San Francisco, 9-13 August.

Ek, D. (2014). \$2 Billion and Counting, 11 November. Retrieved from https://news.spotify.com/us/2014/11/11/2-billion-and-counting/.

Ellis-Petersen, H. (2014). Taylor Swift takes a stand over Spotify music royalties, 5 November. Retrieved from http://www.theguardian.com/music/2014/nov/04/taylorswift-spotify-streaming-album-sales-snub.

Frith, S. (1983). Sound effects: Youth, leisure and the politics of rock'n'roll. London: Constable.

Hirsch, P. M. (1970). The structure of the popular music industry. Survey Research Center. Ann Arbor: University of Michigan.

IFPI (2015). Det norske musikkmarkedet [The Norwegian music market]. Retrieved from http://www.ifpi.no/flere-nyheter/item/79-det-norske-musikkmarkedet-2014.

Lunt, P. \& Sonia, L. (1996). Rethinking the focus group in media and communications research. Journal of Communication 46.2, 79-98.

Mulligan M. (2012). Streaming goes global: Analyzing global music streaming adoption. Retrieved from http://musicindustryblog.files.wordpress.com/2011/11/streaming-goes-global4.pdf.

Rogers, J. (2013). The death and life of the music industry in the digital age. London: Bloomsbury.

Shuker, R. (2013). Understanding popular music culture. 4th edition. London: Routledge.

Suisman, D. (2009). Selling sounds: The commercial revolution in American music. Cambridge, MA: Harvard University Press.

TNS Gallup (2014). InterBuss Q4 2014. Report received via email 12 Sept. 2015.

Wikstrøm P. (2009). The music industry: Music in the cloud. Cambridge: Polity.

Østrem, O. (2014). Skal følge strømmen [Will follow the stream], Klassekampen 16 June. Retrieved from http://www.klassekampen.no/article/20140616/ARTICLE/140619972/1034. 